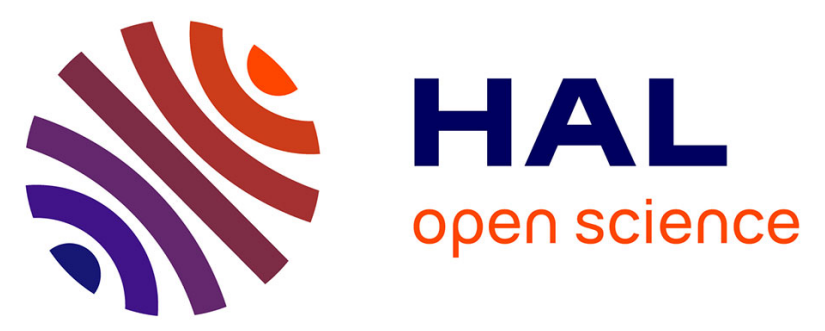

\title{
Modelling Tetraselmis sp. growth-kinetics and optimizing bioactive-compound production through environmental conditions
}

Mouna Dammak, Bilel Hadrich, Mohamed Barkallah, Faiez Hentati, Hajer Ben Hlima, Chantal Pichon, Michel Denis, Imen Fendri, Philippe Michaud, Slim Abdelkafi

\section{To cite this version:}

Mouna Dammak, Bilel Hadrich, Mohamed Barkallah, Faiez Hentati, Hajer Ben Hlima, et al.. Modelling Tetraselmis sp. growth-kinetics and optimizing bioactive-compound production through environmental conditions. Bioresource Technology, 2018, 249, pp.510-518. 10.1016/j.biortech.2017.10.028 . hal-02520703

\section{HAL Id: hal-02520703 \\ https://hal.science/hal-02520703}

Submitted on 25 Jun 2021

HAL is a multi-disciplinary open access archive for the deposit and dissemination of scientific research documents, whether they are published or not. The documents may come from teaching and research institutions in France or abroad, or from public or private research centers.
L'archive ouverte pluridisciplinaire HAL, est destinée au dépôt et à la diffusion de documents scientifiques de niveau recherche, publiés ou non, émanant des établissements d'enseignement et de recherche français ou étrangers, des laboratoires publics ou privés. 


\title{
ACCEPTED MANUSCRIPT
}

\section{Modelling Tetraselmis sp. growth-kinetics and optimizing bioactive-compound production}

\section{through environmental conditions}

\begin{abstract}
Mouna Dammak ${ }^{1}$, Bilel Hadrich ${ }^{1}$, Mohamed Barkallah ${ }^{1}$, Faiez Hentati ${ }^{1}$, Hajer Ben Hlima ${ }^{1}$, Chantal Pichon ${ }^{2}$, Michel Denis ${ }^{3}$, Imen Fendri ${ }^{4}$, Philippe Michaud ${ }^{5}$ and Slim Abdelkafi ${ }^{1, *}$
\end{abstract}

${ }^{1}$ Unité de Biotechnologie des Algues, Biological Engineering Department, National School of Engineers of Sfax, University of Sfax, Sfax, Tunisia

${ }^{2}$ Centre de Biophysique Moléculaire CBM - CNRS, Université d'Orléans, Orleans, France

3 Aix Marseille Université, Université de Toulon, CNRS/INSU, IRD, Institut Méditerranéen d'Océanologie (MIO), 163 avenue de Luminy, Case 901, 13288 Marseille Cedex 09, France.

${ }^{4}$ Laboratoire de Biotechnologie Végétale Appliquée à l'Amélioration des Cultures. Faculty of Sciences, University of Sfax, Sfax, Tunisia

${ }^{5}$ Université Clermont Auvergne, Université Blaise Pascal, Institut Pascal, UMR CNRS 6602, BP 10448, F-63000, Clermont-Ferrand, France.

*Corresponding author: Tel: S. Abdelkafi +21697458923

E-mail adress: $\underline{\text { slim.abdelkafi@enis.tn }}$ 


\section{Abstract :}

The aim of this study is to predict Tetraselmis cells growth-kinetic and to induce the synthesis of bioactive compounds (chlorophylls, carotenoids and starch) with high potential for biotechnological applications. Using the statistical criteria, the Baranyi-Roberts model has been selected to estimate the microalgae growth-kinetic values. The simultaneous effects of salinity, light intensity and $\mathrm{pH}$ of culture medium were investigated to maximize the production of total chlorophylls, carotenoids and starch. The optimal culture conditions for the production of these compounds were found using Box-Behnken Design. Results have showed that total chlorophyll and carotenoids were attained $21.6 \mathrm{mg} \cdot \mathrm{g}^{-1} \mathrm{DW}$ and $0.042 \mathrm{mg} \cdot \mathrm{g}^{-1} \mathrm{DW}$, respectively. In addition, the highest starch content of $0.624 \mathrm{~g} \cdot \mathrm{g}^{-1} \mathrm{DW}$ has been obtained at neutral $\mathrm{pH}$ with high irradiance (182 $\mu \mathrm{mol}$ photons $\left.\cdot \mathrm{m}^{-2} \cdot \mathrm{s}^{-1}\right)$ and low salinity $(20)$. A highly correlation $\left(\mathrm{R}^{2}=0.884\right)$ has been found between the gravimetric and flow cytometric measurements of chlorophyll content.

Keywords: Microalgae; Optimal culture conditions; Carotenoids; Starch; Chlorophylls. 


\section{Introduction}

Many microalgae species have been singled out as sources of value-added compounds such as vitamins, polyunsaturated fatty acids, proteins, pigments, and carbohydrates. Some of them have shown a wide range of biological activities (Khatoon et al., 2014; Delattre et al., 2016). Tetraselmis sp. is a marine microalga that has promising potential particularly in the domains of aquaculture and biofuel production (Hemaiswarya et al., 2011; Yao et al., 2013). Tetraselmis species are able to produce high amounts of starch, up to $42-62.1 \%$ of total dry weight (DW), which makes them a potential source of fermentable sugar for bioethanol production (Yao et al., 2012; Dammak et al., 2017). In order to improve the valorisation of Tetraselmis biomass economically in this field, it is necessary to enhance the contents of high value compounds and starch as well as the Tetraselmis productivity and the biomass treatment by a biorefinery strategy (Yao et al., 2012). Various environmental stress-conditions such as irradiance, salinity, pH and temperature have been described in literature as being parameters that might influence the production of some biochemical compounds in microalgae (García et al., 2012; Markou et al., 2012; Yao et al., 2013; Khatoon et al., 2014; Sun et al., 2014; Takeshita et al., 2014; Dammak et al., 2016). Several studies reported that under different stress conditions, the microalgae produce bioactive compounds as a cell-protecting mechanism (El-Kassas and El-Sheekh, 2016). Li et al. (2015) demonstrated that starch is the dominant sink for energy and short-term carbon storage in response to environmental stresses. Regarding carotenoids synthesis, the isomerisation of its precursor (isopentenyl pyrophosphate (IPP)), to dimethylallyl diphosphate, is catalysed by isopentenyl pyrophosphate isomerase (IPI), and transcripts of IPI genes increased in response to oxidative stress (Han et al., 2012). Indeed, the microalgae are harvested commercially to extract chlorophyll that is used in drugs and foods as a green colouring agent (E140). Chlorophylls, the essential photoreceptors in photosynthesis, are the principal pigments giving the characteristic green color of Chlorophyceae (Koca et al., 2007). Additionally, some researchers suggested that 


\section{ACCEPTED MANUSCRIPT}

chlorophyll metabolism influenced all of the whole photosynthetic machinery (Tanaka and Tanaka, 2006). Decreasing salinity was shown to enhance starch production by marine microalgae such as Tetraselmis subcordiformis (Yao et al., 2013) and Dunaliella (Chen and Jiang, 2009). Light and $\mathrm{pH}$ were reported to highly influence microalgae production (Juneja et al., 2013). Maximum starch accumulation has been attained when microalgae were exposed to stress conditions. They adapted themselves to these conditions shifting their metabolism towards storing energy compounds (Kirrolia et al., 2011). Recent studies demonstrated that chlorophyll and starch contents of Tetraselmis subcordiformis strains have been inversely correlated with $\mathrm{NaCl}$ concentration in the culture medium (Yao et al., 2013).

The present study aims at (i) analyzing kinetic models describing the Tetraselmis cell growth, (ii) optimizing the salinity, irradiance and $\mathrm{pH}$ to reach the highest content in value-added bioactive compounds (total chlorophyll, carotenoids and starch) by Response Surface Methodology (RSM) and (iii) studying their influence on the metabolism of Tetraselmis sp. grown under single-stage cultivation process. The correlation between spectrometry and flow cytometry methods for total chlorophyll estimation was also investigated.

\section{Material and methods}

\subsection{Microalgal strain maintenance and growth conditions}

The green microalga Tetraselmis sp. $\left(\mathrm{V}_{2}\right)$ was isolated from the Gulf of Gabes (Mediterranean Sea) along the coast of Sidi Mansour (Tunisia). The culture was maintained in F/2 medium (Guillard, 1975) at $25 \pm 1^{\circ} \mathrm{C}$. Irradiance of $84 \mu \mathrm{mol}$ photons $\cdot \mathrm{m}^{-2} \cdot \mathrm{s}^{-1}$ with $12 \mathrm{~h}$-light $/ 12 \mathrm{~h}$-dark photoperiod was provided by a white fluorescent lamp (Compact Fluorescent Lamp, Superlight, Tunisia).

\subsection{Assays}

The cell pellets from $1 \mathrm{~mL}$ culture were sonicated in $1 \mathrm{~mL}$ ethanol at $65^{\circ} \mathrm{C}$ for $30 \mathrm{~min}$ and the extracts were centrifuged at $5000 \times g$ for $5 \mathrm{~min}$. The pellets were used for starch content 


\section{ACCEPTED MANUSCRIPT}

determination according to Xiao et al. (2006) and Hirst et al. (1972) using iodine reagent (2\% (w/v) potassium iodide and $0.2 \%(\mathrm{w} / \mathrm{v})$ iodine).The supernatants were used for absorbance measurements $\left(\mathrm{A}_{666 \mathrm{~nm}}, \mathrm{~A}_{653 \mathrm{~nm}}\right.$ and $\left.\mathrm{A}_{470 \mathrm{~nm}}\right)$ The total chlorophyll and carotenoid contents were calculated according to Lichtenthaler and Wellburn (1985) and Kumar et al. (2010).

The content determinations of lipids, proteins, ashes, potassium, magnesium, zinc, manganese, calcium, iron and copper were carried out according to protocols described by Dahmen et al. (2014) and Saddoud et al. (2009).

\subsection{Experimental kinetics}

The cell abundance was expressed as a function of the experiment duration. It was monitored by absorbance $\left(\mathrm{A}_{680 \mathrm{~nm}}\right)$ measurement as described by Schmidt et al. (2016) and Nguyen and Rittmann (2016).

This experiment was achieved in duplicate and data were expressed as mean values with standard deviation $( \pm \mathrm{SD})$.

\subsection{Kinetic modelling}

Four models were chosen to account for Tetraselmis cell growth kinetics: logistic, logistic with lag, modified Gompertz and Baranyi-Roberts (Mohamed et al., 2014). The sigmoid-shaped growth-model can precisely depict the lag, exponential and stationary phases of cell growth (Arbib et al., 2014).

\subsubsection{Logistic model}

The time dependent rise in biomass concentration following the Verhulst logistic function (Vogels et al., 1975) was represented by equation 1 (Eq. 1):

$$
\frac{d X}{d t}=\mu_{\max } \cdot\left(1-\frac{X}{X_{\max }}\right) \cdot X
$$

where $d X / d t$ is the microalgae growth rate $\left(\right.$ day $\left.^{-1}\right), \mu_{m a x}$ is the microalgae maximum specific growth rate $\left(\right.$ day $\left.^{-1}\right), X$ and $X_{\max }$ refer to cell absorbance at time $t$ and at the maximum, respectively. 


\section{ACCEPTED MANUSCRIPT}

The temporal increase of cell absorbance $(X(t))$ was determined by integrating the above equation

(Eq. 1), as expressed by the logistic equation (Eq. 2) (Mohamed et al., 2014; Chang et al., 2016):

$$
X(t)=\frac{X_{0} \cdot e^{\mu_{\max } \cdot t}}{1-\frac{X_{0}}{X_{\max }} \cdot\left(1-e^{\mu_{\max } \cdot t}\right)}
$$

where $X_{0}$ is the initial cell-suspension absorbance at time $0\left(X_{0}=0.0425\right)$.

\subsubsection{Logistic with lag model}

A new parameter setting of the logistic model (Eq. 2) was applied by Zwietering et al. (1990).

They incorporated an additional term $\lambda$ (day), related to the first phase (lag phase) of microalgae growth kinetics as shown in (Eq. 3):

$$
X(t)=X_{0}+\frac{X_{\max }-X_{0}}{1+e^{\left\{\left(\frac{4 \cdot \mu_{\max }}{X_{\max }-X_{0}}\right) \cdot(\lambda-t)+2\right\}}}
$$

\subsubsection{Gompertz model}

The modified Gompertz model including the previous term, $\lambda$ (day) relevant to biomass concentration parameters was rewritten by Mohamed et al. (2014) through (Eq. 4):

$X(t)=X_{0}+\left(X_{\max }-X_{0}\right) \cdot$

\subsubsection{Baranyi and Roberts model}

A new family of bacterial growth models proposed by Baranyi and Roberts (1994) applied the first order differential function for the time dependent specific growth rate, $\mu(t)$, as defined by (Eq. 5):

$\mu(t)=\frac{1}{X} \cdot \frac{d X}{d t}=\mu_{\max } \cdot \alpha(t) \cdot f(t)$

where $\alpha(t)$ is the adjustment function that represents the inoculum adaptation in the culture.

The above expression was transposed to a microalgae growth model through a linear equation by Mohamed et al. (2014), as shown in (Eq. 6) and (Eq. 7): 


$$
X(t)=X_{0}+\mu_{\max } \cdot B(t)-\ln \left(1+\frac{e^{\left(\mu_{\max } \cdot B(t)\right)}-1}{e^{\left(X_{\max }-X_{0}\right)}}\right)
$$

where

$$
B(t)=t+\frac{1}{\mu_{\max }} \cdot \ln \left(e^{-\mu_{\max } \cdot t}+e^{-\mu_{\max } \cdot \lambda}-e^{-\mu_{\max } \cdot(t+\lambda)}\right)
$$

\subsubsection{Statistical treatment}

A Matlab algorithm was carried out and applied to identify the parameters of Eqs. 2, 3, 4, 6 and 7, via the fitting procedure and to compare the experimental data and the fitted ones. The fitting procedure of Tetraselmis sp. growth data was established using non-linear least-square regression method. Four statistical parameters were chosen to check the model validation: the determination coefficient $\left(\mathrm{R}^{2}\right)$, the adjusted determination coefficient $\left(\operatorname{Adj} \mathrm{R}^{2}\right)$, the sum of square error (SSE) and the root mean square error (RMSE).

All model coefficients were determined with $95 \%$ confidence level (i.e. $P$-value $<0.05$ ).

\subsection{Experimental design}

Optimization experiments were carried out in two replicates and in $250 \mathrm{~mL}$ Erlenmeyer flasks with a working volume of $150 \mathrm{~mL}$ inoculated with $15 \mathrm{~mL}$ of culture. The chosen salinity, irradiance and $\mathrm{pH}$ values are reported in Table 1.

After growth (late logarithmic phase (15 days)), the biomass was harvested by centrifugation at $5000 \times g$ for $10 \mathrm{~min}$ and dried at $105^{\circ} \mathrm{C}$ for 24 hours until reaching a constant weight to quantify DW.

\subsection{Statistical analysis}

The influence of salinity, irradiance and $\mathrm{pH}$ on metabolite content of Tetraselmis sp. was assessed through a Box-Behnken Design (BBD) (Box and Behnken, 1960). Table 1 reports the selected values of variables by defining three experimental levels ( -1 : low, 0 : medium and +1 : high). The RSM was used to optimise pigment and starch productions as well as the interaction effects of the three factors on three responses: total chlorophyll, carotenoid and starch contents. 


\section{ACCEPTED MANUSCRIPT}

The multiple regression analysis was utilized for fitting the experimental results with a second order polynomial equation (Eq. 8).

$\hat{Y}_{i=} \beta_{0}+\sum \beta_{i} x_{i}+\sum \beta_{i i} x_{i}^{2}+\sum \beta_{i j} x_{i} x_{j}$

where $\hat{Y}_{i}$ : calculated response variable; $\beta_{0}$ : constant; $x_{i}$ and $x_{j}$ : coded variable ranging between the minimum and the maximum levels of different factors; $\beta_{i}, \beta_{i i}$ and $\beta_{i j}$ : coefficients for the linear, quadratic, and interaction effects, respectively.

In this study, the experiment design was based on 15 combinations of variable values for optimising culture conditions (Table 2). Three replicates at central points were carried out to assess the experimental variance. The experiment design responses were the total chlorophyll $\left(Y_{l}\right)$, carotenoid $\left(Y_{2}\right)$ and starch $\left(Y_{3}\right)$ contents. The model quality was evaluated by the $\mathrm{R}^{2}$ and the Adj $\mathrm{R}^{2}$. The statistical significance of the model and the regression coefficients were tested by both Fisher-test ( $F$-value and analysis of variance (ANOVA)) and Student-test (data not shown). Experimental results were analysed using STATISTICA Software 8.0 (Stat Soft. Inc 2008). The significant terms (regression coefficients and their interactions) correspond to those having a $P$ value $<0.05$ ( significance at $95 \%$ )

\subsection{Flow cytometry (FCM)}

Cultures of Tetraselmis sp. were analyzed using a LSR (Becton Dickinson Biosciences) flow cytometer equipped with a $488 \mathrm{~nm}$ argon laser, to optimize culture conditions with respect to cell red fluorescence intensity (chlorophyll content). The cell red fluorescence was collected through a 613/682 nm band-pass filter.

\subsection{Microscopy}

Total chlorophyll content in microalgae was quantified with an epifluorescent microscope, Observer Z1 (Carl Zeiss, Oberkochen, Germany), with a $470 \mathrm{~nm}$ excitation wavelength and collecting fluorescence at $700 \mathrm{~nm}$. 


\section{Results and discussion}

\subsection{Biochemical composition of Tetraselmis sp.}

The biochemical analysis of Tetraselmis sp. grown under basic environmental conditions (salinity: 40; irradiance: $84 \mu \mathrm{mol}$ photons $\cdot \mathrm{m}^{-2} \cdot \mathrm{s}^{-1} ; \mathrm{pH}$ 7) highlight high protein $\left(250 \pm 2.4 \mathrm{mg} \cdot \mathrm{g}^{-1} \mathrm{DW}\right)$, lipid $\left(195 \pm 2.1 \mathrm{mg} \cdot \mathrm{g}^{-1} \mathrm{DW}\right)$, and starch contents $\left(340 \pm 1.2 \mathrm{mg} \cdot \mathrm{g}^{-1} \mathrm{DW}\right)$ as well as significant amounts of ashes $\left(166.81 \pm 2.49 \mathrm{mg} \cdot \mathrm{g}^{-1} \mathrm{DW}\right)$, total chlorophyll $\left(18.08 \pm 1.16 \mathrm{mg} \cdot \mathrm{g}^{-1} \mathrm{DW}\right)$ and carotenoids $\left(0.025 \pm 0.002 \mathrm{mg} \cdot \mathrm{g}^{-1} \mathrm{DW}\right)$. The investigated Tetraselmis sp. showed also higher magnesium $\left(14.263 \pm 0.041 \mathrm{mg} \cdot \mathrm{g}^{-1} \mathrm{DW}\right)$, calcium $\left(5.263 \pm 0.160 \mathrm{mg} \cdot \mathrm{g}^{-1} \mathrm{DW}\right)$ and manganese $(0.270 \pm 0.006$ $\left.\mathrm{mg} \cdot \mathrm{g}^{-1} \mathrm{DW}\right)$ contents than those of Picochlorum sp. $(0.254 \pm 0.020,1.478 \pm 0.250,0.008 \pm 0.001$ $\mathrm{mg} \cdot \mathrm{g}^{-1} \mathrm{DW}$, respectively) reported by Dahmen et al. (2014).

\subsection{Experimental growth data and kinetic model assessment}

The maximum cells absorbance $\left(X_{\max }\right)$ and the maximum specific growth rates $\left(\mu_{\max }\right)$ for Tetraselmis sp. growth-kinetics were determined using logistic, logistic with lag and modified Gompertz and Baranyi-Roberts models. The $X_{\max }$ and $\mu_{\max }$ for predicted cell growth-kinetics, as well as the curve fitting quality of the four models are reported in Table 3. Fig. 1 illustrates the representation by the four models of Tetraselmis sp. experimental growth-kinetics with microalgae grown in F/2-medium under basic environmental conditions (salinity: 40; irradiance: $84 \mu \mathrm{mol}$ photons $\left.\cdot \mathrm{m}^{-2} \cdot \mathrm{s}^{-1} ; \mathrm{pH} 7\right)$. The maximum specific growth-rate varied from 0.034 to 0.416 day $^{-1}$. The $\mathrm{R}^{2}$ and the $\mathrm{Adj}^{2}$ were $>95 \%$ for the four models. The RMSE and SSE parameters supported a good fitting by all of the used models and they singled out the best two models (Baranyi-Roberts and Gompertz models) by their lowest values (Table 3).

From statistical considerations, Baranyi-Roberts and modified Gompertz models provided RMSE values of 0.018 and 0.019 respectively, and the same SSE (0.004). The growth-kinetic parameters distinguished the Baranyi-Roberts model as the one providing the best fit of the experimental Tetraselmis sp. growth-curve. The predicted culture yield derived from the Baranyi-Roberts model gave the highest $\mu_{\max }$ of $0.206 \mathrm{day}^{-1}\left(0.0085 \mathrm{~h}^{-1}\right)$ and the largest maximum absorbance 


\section{ACCEPTED MANUSCRIPT}

value, $X_{\max }=0.483$. Consequently, the Baranyi-Roberts model was selected to describe the Tetraselmis sp. growth-kinetics (Fig. 1).

The $\mu_{\max }$ was higher than that determined by Mohamed et al. (2014) for Tetraselmis sp. FTC209 grown under the photoautotrophic conditions in W-20 medium $\left(0.0045 \mathrm{~h}^{-1}\right)$.

\subsection{Effect of independent variables on pigments production}

\subsubsection{Total chlorophyll production optimization}

The experimental results of different BBD levels are reported in Table 2. A quadratic equation was used to represent the outputs of total chlorophyll $\left(Y_{1}\right)$ production model (Eq. 9):

$\hat{Y}_{l}=12.67-2.19 x_{1}+2.43 x_{1}^{2}-4.17 x_{2}-3.50 x_{3}-1.45 x_{3}^{2}-1.03 x_{1} x_{2}-1.05 x_{2} x_{3}$

The $\mathrm{R}^{2}$ of this quadratic equation from ANOVA output (Table 4) is high (98.87\%) and it draws attention to a good correlation between the experimental values of total chlorophyll production and the related values derived from Eq. (9). This relationship is supported by the result displayed in Fig. 2A. Indeed, the $y$-intercepts of the mathematical adjustment does not differ significantly from zero and the slope is close to unit. ANOVA test (Table 4) shows the non-significance of lack of fit for total chlorophyll production response $(P$-value $>0.05)$. This proves that the presented model is valid and it can be adopted in this work. When total chlorophyll content was used as response, all the linear effects were very significant, and irradiance $\left(x_{2}, P\right.$-value $\left.=0.001<0.05\right)$ was the most significant factor (Table 4). In addition, negative regression coefficients of all the linear effect factors were observed (Eq. 9), which indicates that the total chlorophyll production increased at low levels of salinity, irradiance and $\mathrm{pH}$. The interactions between $x_{1}$ and $x_{2}$ and between $x_{2}$ and $x_{3}$, also showed their significant and negative effects on total chlorophyll synthesis by Tetraselmis sp. $(P$-value $<0.05)$. 


\section{ACCEPTED MANUSCRIPT}

The optimal value of total chlorophyll content and interactions between the environmental culture conditions are shown in the two dimensions (2D) and three dimensions (3D) response surface plots (Fig. 3A). When the $\mathrm{pH}$ was fixed at a low level $(\mathrm{pH} 6.5)$, the highest total chlorophyll content of Tetraselmis sp. (from 19 to $21.6 \mathrm{mg} \cdot \mathrm{g}^{-1} \mathrm{DW}$ ) was obtained at low salinity (between 20 and 25) and irradiance (from 84 to $100 \mu \mathrm{mol}$ photons $\cdot \mathrm{m}^{-2} \cdot \mathrm{s}^{-1}$ ). The maximum total chlorophyll level was reached at pH 6.5; salinity: 20 and irradiance: $84 \mu \mathrm{mol}$ photons $\cdot \mathrm{m}^{-2} \cdot \mathrm{s}^{-1}$ (Fig. 3A).

This result is similar to that found by Yao et al. (2013) with the following culture-factors: salinity: 27; irradiance: $150 \mu \mathrm{mol}$ photons $\cdot \mathrm{m}^{-2} \cdot \mathrm{s}^{-1}$ being under nitrogen repletion. Our results showed an increase of total chlorophyll biosynthesis when cells were exposed to low salinity. In agreement with our results, El-Kassas and El-Sheekh (2016) reported that excess salinity (40 ppm) decreased chlorophyll a content in Tetraselmis tetrathele. This was consistent with the photosynthesis inhibition under high salinity observed with Tetraselmis species and other microalgae. Actually, this could result from protein-synthesis inhibition (Kirst, 1990; Sudhir and Murthy, 2004; Yao et al., 2013). Murata et al. (2007) also proposed that photosynthesis inhibition at high salinity might result from protein de novo bio-synthesis inhibition, especially D1 protein that could impair the photo-damaged PSII repair cycle.

\subsubsection{Carotenoids production optimization}

The experimental data for carotenoids production $\left(Y_{2}\right.$, Table 2) were fitted by the following quadratic equation (Eq. 10), established by the multiple regression analysis:

$\hat{Y}_{2}=0.017+0.005 x_{1}-0.005 x_{2}+0.005 x_{2}^{2}-0.006 x_{3}^{2}+0.010 x_{1} x_{2}-0.004 x_{2} x_{3}$

The $\mathrm{R}^{2}$ value of $92.10 \%$ linked to carotenoids production according to Eq. (10) was relatively high (Table 5). In addition, the $y$-intercepts of the mathematical adjustment do not differ significantly from zero and the slope is close to the unit (Fig. 2B). So, these results express a good 


\section{ACCEPTED MANUSCRIPT}

agreement between both the experimental and the predicted data. The value-validity analysis revealed that the lack of fit for carotenoid production response was not significant $(P$ - value $>$ 0.05) which indicated also the good quality of the model (Table 5).

Salinity $\left(x_{1}\right)$, irradiance $\left(x_{2}\right)$ and their interactive effect $\left(x_{1} x_{2}\right)$ have the most significant effects on carotenoid biosynthesis $(P$-value $\leq 0.05)$ (Table 5). The quadratic effect of irradiance $\left(x_{2}{ }^{2}\right)$ and $\mathrm{pH}$ $\left(x_{3}^{2}\right)$ and their interaction $\left(x_{2} x_{3}\right)$ were also significant, but the linear effect of $\mathrm{pH}\left(x_{3}\right)$ (Eq. 10), was not significant.

When testing the high range of salinity $\left(x_{1}\right)$ and irradiance $\left(x_{2}\right)$ at $\mathrm{pH} 7$, the carotenoids content increased rapidly with both factors (Fig. 3B). The optimized carotenoids content could thus be obtained at neutral $\mathrm{pH}$ with a high salinity: 40 and irradiance: $182 \mu \mathrm{mol}$ photons $\cdot \mathrm{m}^{-2} \cdot \mathrm{s}^{-1}$.

\subsubsection{Effect of factors on carotenoids/chlorophylls ratio $\left(Y_{2} / Y_{1}\right)$}

In Table 2, run 3, salinity (20) was low as well as the produced carotenoid/chlorophyll ratio $\left(Y_{2} / Y_{1}\right)(0.000428)$. In run 4, irradiance and $\mathrm{pH}$ were equal to those of run 3 , salinity was fixed at 40 and $Y_{2} / Y_{1}$ increased (0.005479) about 13 -fold in response to salinity stress. Our results are in agreement with those reported by Ben Moussa-Dahmen et al. (2016) who demonstrated that high salinity can induce oxidative stress and decrease total-chlorophyll production by reducing PSII activity. Likenwise, Pancha et al. (2015) reported that high salinity in the culture medium of the Scenedesmus sp. and Nannochloropsis sp. increased the carotenoid/chlorophyll $a$ ratio suggesting an antenna-size reduction and a better photosynthetic-activity protection against the photooxidative damages. Previous studies reported that for cultures upon increased salinity, the decrease in photosynthesis quantum-efficiency resulted in low total chlorophyll synthesis due to the highsalinity negative effect on photo-phosphorylation and /or electron transport processes (Kirrolia et al., 2011).

The carotenoid/chlorophyll ratio was high in run 4 with salinity and light intensity at high level (level +1$)$, but the $Y_{2} / Y_{1}$ ratio decreased about 4-fold by setting the same parameters at level 0 and pH remaining neutral (run 13). The cells photo-protection against photo-damages was thus 


\section{ACCEPTED MANUSCRIPT}

enhanced under excess of irradiance (Yao et al., 2013). In contrast, high photosynthetic activity was observed under favourable conditions (low $Y_{2} / Y_{1}$ ratio) leading to a better use of irradiance for photosynthesis (runs 13, 14 and 15). In this respect, many previous studies reported that under light stress, the transcripts of PDS and PTOX genes, phytoene desaturase (PDS) and plastid terminal oxidase (PTOX), increased simultaneously in H. pluvialis. Such studies suggested that these two enzymes may dehydrogenate phytoene, remove excess electrons and then prevent the excess ROS formation and the photosynthetic electron transport chain over-reduction (Li et al., 2010).

\subsubsection{Models validation}

To confirm the relevance of pigment models for predicting maximal pigment synthesis, additional experiments using optimized culture conditions were made. The total chlorophyll content reached $21.6 \mathrm{mg} \cdot \mathrm{g}^{-1} \mathrm{DW}$, expressing about 1.2 - fold increase with respect to the total chlorophyll content obtained under basic environmental condition.

Under the optimized culture conditions, the carotenoids production reached $0.042 \mathrm{mg} \cdot \mathrm{g}^{-1} \mathrm{DW}$, a value 1.68 times higher than under basic environmental conditions. The RSM statistical method using BBD was successfully applied to study the effect of independent variables and to optimise pigments production.

\subsection{Effect of independent variables on starch production}

\subsubsection{Starch production optimisation}

The starch content response of Tetraselmis sp. as derived from BBD experiments (Table 2), was affected by the most environmental factors. Runs 3, 6 and 14 gave the best starch content $\left(Y_{3}\right)$, highlighting the strong influence of the three factors on starch biosynthesis (Table 2).

The experimental starch production $\left(Y_{3}\right)$ in Tetraselmis sp. was represented by (Eq. 11).

$$
\hat{Y}_{3}=0.50+0.13 x_{2}-0.12 x_{2}^{2}-0.05 x_{3}-0.12 x_{3}^{2}-0.12 x_{1} x_{2}-0.07 x_{1} x_{3}-0.05 x_{2} x_{3}
$$


The variance analysis of starch production model (Table 6) showed that Eq. 11 yielded a high Adj $\mathrm{R}^{2}(97.57 \%)$ and a high $\mathrm{R}^{2}(99.13 \%)$, leading to a distribution of observed and predicted starch content values $\left(Y_{3}\right)$ aligned along a straight line whose slope $=1$ ( Fig. 2C). This slope, highlighted the good quality of the regression model consistently with the non-significant lack of fit $(P$-value $=0.4>0.05 ;$ Table 6 )

According to (Eq. 11) and the related variance analysis (Table 6), starch production was significantly affected by the linear and quadratic effects of irradiance and $\mathrm{pH}$, as well as the interactive effects of all factors $(P$-value $<0.05)$.

The 2D and 3D graphs (Fig. 3C), display the interactive effects of salinity and irradiance at $\mathrm{pH} 7$ on starch production. The hyperbolic shape of both term contour-plot $\left(x_{1} x_{2}\right)$, revealed the perfect interaction between both variables. As shown in Fig. 3C, starch synthesis increased continuously with an increasing irradiance and a decreasing salinity. The maximum starch content $\left(0.624 \mathrm{~g} \cdot \mathrm{g}^{-1}\right.$ DW) was attained at neutral $\mathrm{pH}$, low salinity: 20 and high irradiance: $182 \mu \mathrm{mol}$ photons $\cdot \mathrm{m}^{-2} \cdot \mathrm{s}^{-1}$. In this research, different irradiances were chosen to ameliorate starch synthesis as illustrated in Fig. 3C, which illustrates starch accumulation after rising irradiance from 84 to $182 \mu \mathrm{mol}$ photons $\cdot \mathrm{m}^{-2} \cdot \mathrm{s}^{-1}$. This finding is consistent with previous studies demonstrating that certain levels of irradiance should be required for high level of carbohydrate production. Ho et al. (2012) and Sun et al. (2014) also documented an increase of the carbohydrate content when rising irradiance from 60 to $420 \mu \mathrm{mol}$ photons $\cdot \mathrm{m}^{-2} \cdot \mathrm{s}^{-1}$ and from 50 to $100 \mu \mathrm{mol}$ photons $\cdot \mathrm{m}^{-2} \cdot \mathrm{s}^{-1}$, respectively. In run 10 (Table 2), the increased irradiance $\left(182 \mu \mathrm{mol}\right.$ photons $\left.\cdot \mathrm{m}^{-2} \cdot \mathrm{s}^{-1}\right)$ disturbed the cell photoprotection mechanism, which decreased the photosynthetic activity and leaded to Tetraselmis sp. photo-inhibition. Brányiková et al. (2011) reported that Chlorella vulgaris (Beijerinck CCALA 924) produced high starch content $(60 \% \mathrm{DW})$ under high irradiance $\left(780 \mu \mathrm{mol}\right.$ photons $\left.\cdot \mathrm{m}^{-2} \cdot \mathrm{s}^{-1}\right) . \mathrm{It}$ was also mentioned by Yao et al. (2012) that high irradiance $\left(200 \mu \mathrm{mol}\right.$ photons $\left.\cdot \mathrm{m}^{-2} \cdot \mathrm{s}^{-1}\right)$ and sulfur deprivation could induce starch accumulation $(62.1 \%$ DW) in T. subcordiformis, while, upon 


\section{ACCEPTED MANUSCRIPT}

nitrogen deprivation and irradiance at $50 \mu \mathrm{mol}$ photons $\cdot \mathrm{m}^{-2} \cdot \mathrm{s}^{-1}$, this strain reached starch content of $49.3 \%$ DW. A high value of starch content (38.6\% DW) was also reported by Yao et al. (2013) with Tetraselmis subcordiformis grown under standard salinity (27), irradiance of $150 \mu \mathrm{mol}$ photons $\cdot \mathrm{m}^{-2} \cdot \mathrm{s}^{-1}$ and under nitrogen repletion. This level increased up to $58.2 \% \mathrm{DW}$ in response to low culture salinity (5.4), irradiance of $150 \mu \mathrm{mol}$ photons $\cdot \mathrm{m}^{-2} \cdot \mathrm{s}^{-1}$ and nitrogen deprivation. Interestingly, in contrast to starch contents reported in the literature, our study achieved a higher content (62.4\% DW) when Tetraselmis sp. was exposed to the following conditions: salinity: 20 , irradiance: $182 \mu \mathrm{mol}$ photons $\cdot \mathrm{m}^{-2} \cdot \mathrm{s}^{-1}$ and $\mathrm{pH}$ 7. In fact, the starch content produced by the isolated Tetraselmis sp. V2 strain was higher than those obtained with Tetraselmis subcordiformis (Yao et al., 2012; 2013), Chlorella vulgaris Beijerinck P 12 (Dragone et al., 2011), Chlorella vulgaris Beijerinck CCALA 924 (Brányiková et al., 2011) and Dunaliella tertiolecta ATCC 30929 (Ike et al., 1997) . These experiments suggest that Tetraselmis sp. has a relevant potential for starch production.

\subsubsection{Effect of factors on starch and chlorophyll contents relationship}

The low total chlorophyll $\left(7.3 \mathrm{mg} \cdot \mathrm{g}^{-1} \mathrm{DW}\right)$ production and starch content $(35 \% \mathrm{DW})$ in run 4 under high salinity (40), high irradiance $\left(182 \mu \mathrm{mol}\right.$ photons $\left.\cdot \mathrm{m}^{-2} \cdot \mathrm{s}^{-1}\right)$ and neutral $\mathrm{pH}$ could result from the extrusion of excess sodium ions $\left(\mathrm{Na}^{+}\right)$from microalgae cytoplasm and therefore mitigate the negative effect of high salinity on cells. Indeed, Strizh et al. (2004) found two isomers of the $\mathrm{Na}^{+}$-ATPase in the green microalgae Tetraselmis viridis whose $\mathrm{Na}^{+}$pumps regulated the osmotic pressure. The $\mathrm{Na}^{+}$extrusion requires ATP which reduces ATP supply for the cells needs such as $\mathrm{CO}_{2}$ fixation and this decreases biomass production and starch accumulation.

Similarly, Yao et al. (2013) showed that the high salinity of the culture medium decreased the growth of Tetraselmis subcordiformis and the protein and chlorophyll biosynthesis by this strain. These conditions induced starch catabolism by up-regulating respiration. The green microalgae Tetraselmis subcordiformis cultivated for 6 days under high salinity (54 and 67.5), $150 \mu$ mol 


\section{ACCEPTED MANUSCRIPT}

photons $\cdot \mathrm{m}^{-2} \cdot \mathrm{s}^{-1}$ and with nitrogen repletion, produced a lower starch level than under standard salinity (27). This phenomenon was explained by the allocation of fixed $\mathrm{CO}_{2}$ from photosynthesis to the production of low-molecular-weight organic osmolytes to acclimate cells to hyper-osmotic stress. This hypothesis was supported by Richter and Kirst (1987) who reported that in hypersaline environments, the microalga Platymonas subcordiformis accumulated the mannitol compounds for osmo-regulation.

Chen and Jiang (2009) also found low starch content in Dunaliella sp. biomass obtained from culture media with high salinity. According to Khatoon et al. (2014), the Tetraselmis sp. showed higher carbohydrate contents when grown with a salinity of 30 than 40 and 20 . In contrast, Siaut et al. (2011) reported that starch production in the freshwater microalgae Chlamydomonas reinhardtii raised by increasing salinity.

In run 6 (Table 2), total chlorophyll content reached a high value $\left(15 \mathrm{mg} \cdot \mathrm{g}^{-1} \mathrm{DW}\right)$ as well as starch content (50\% DW) under high salinity (40), irradiance $\left(133 \mu \mathrm{mol}\right.$ photons $\cdot \mathrm{m}^{-2} \cdot \mathrm{s}^{-1}$, zero level) and $\mathrm{pH}$ 6. However, in run 8 where salinity and irradiance were maintained, increasing $\mathrm{pH}$ to 8 lowered the photosynthetic activity and starch synthesis.

In this study, at low salinity (20 and 30$)$ and at high irradiance $\left(182 \mu \mathrm{mol}\right.$ photons $\left.\cdot \mathrm{m}^{-2} \cdot \mathrm{s}^{-1}\right)$, the starch production under alkaline medium (28\% DW- run 12) was lower than those established under neutral $\mathrm{pH}(64 \%$ DW-run 3) and under acidic medium (49\% DW- run 10) (Table 2). The present results are similar to those of Khatoon et al. (2014) who obtained higher carbohydrate content when Tetraselmis sp. was grown at $\mathrm{pH}$ 7.5. By contrast, Chlorella ellipsoidea yielded a high carbohydrate content at $\mathrm{pH}$ 9, while this level decreased at $\mathrm{pH} 10$ and 4 (Khalil et al., 2010).

\subsubsection{Model validation}

In this study, cultivating Tetraselmis sp. under the optimized culture conditions for 15 days leads to a maximum (62\%) starch content that was about twice that under basic environmental 


\section{ACCEPTED MANUSCRIPT}

condition. This result demonstrates the high efficiency of the Box-Behnken Design to achieve the highest starch production.

\subsection{Flow cytometry and gravimetric for chlorophyll estimation}

In this study, cell chlorophyll content was quantified through auto-fluorescence by flow cytometry. Fig. 4B displays the ratio of chlorophyll autofluorescence optimal value $(=79.36$ arbitrary units (a.u.)) results related to the RSM runs. The analysis of total chlorophyll production by FCM for the RSM experimental conditions (Fig. 4B) showed an increase in total chlorophyll content correlated with a decrease of salinity (from run 2 to run 1 , for example, Table 2), irradiance (from run 3 to run 1) and $\mathrm{pH}$ (from run 7 to run 5). These results are similar to those obtained after estimation of total chlorophyll content by the gravimetric method (Table 2 and Fig. 4A). The lowest total chlorophyll content was related to cultures of Tetraselmis sp. exposed to high irradiance, as seen in runs 4 and 12 (Fig. 4). These results are consistent with the morphological changes linked to the chlorophyll content in Tetraselmis sp. cells corresponding to conditions 1, 12 and 14 of RSM cultures. An important fluorescence intensity, cell size and number of chlorophyll biomolecules were reported for Tetraselmis cells cultivated under conditions 1 (salinity: 20; irradiance: $84 \mu \mathrm{mol}$ photons $\cdot \mathrm{m}^{-2} \cdot \mathrm{s}^{-1} ; \mathrm{pH}$ 7) but these granulation fluorescences decreased under conditions 14 (salinity: 30; irradiance: $133 \mu \mathrm{mol}$ photons $\cdot \mathrm{m}^{-2} \cdot \mathrm{s}^{-1}$; $\mathrm{pH}$ 7) applied to cells cultivated under conditions 12 (salinity: 30; irradiance: $182 \mu \mathrm{mol}$ photons $\cdot \mathrm{m}^{-2} \cdot \mathrm{s}^{-1} ; \mathrm{pH}$ 8). Similar to findings reported in Table 2 and illustrated by Fig. 4, these results suggest that the total chlorophyll production increased after the decrease of $\mathrm{pH}$, salinity and irradiance.

As shown in Fig. 5, a significant degree of correlation was achieved with an $\mathrm{R}^{2}$ of 0.884 between the FCM red fluorescence signal $(613 / 682 \mathrm{~nm})$ and the total chlorophyll content estimated by the gravimetric method $(653 / 666 \mathrm{~nm})$. Hence, the present study illustrates the possibility of estimating total chlorophyll content in green microalgae in response to different environmental culture 


\section{ACCEPTED MANUSCRIPT}

conditions by FCM. However, the chlorophyll red-fluorescence signal, expressed in a.u., is highly dependent on the instrument and its setting. One step ahead in that direction could be to normalise the sample red fluorescence signal by that of standards beads added to the sample. Such normalisation would enable the comparison of observations made at different times or even with different instruments. Nevertheless, in order to benefit from the capacity of FCM, analyze a large quantity of samples cleanly and rapidly (Davey and Kell, 1996) and achieve a valid and rapid method for chlorophyll estimation in response to different environmental culture conditions, the calibration of the red fluorescence signal with conventional techniques (spectro-fluorometry, HPLC) will remain necessary.

\section{Conclusions}

The Baranyi-Roberts model was found to be efficient for fitting Tetraselmis growth kinetic through different statistical validations. Tetraselmis sp. showed also a high $(62.4 \% \mathrm{DW})$ starch content under low salinity, high irradiance and neutral $\mathrm{pH}$. Thus, it can be suitable for bioethanol production. The Tetraselmis cells yielded a total chlorophyll content of $21.6 \mathrm{mg} \cdot \mathrm{g}^{-1} \mathrm{DW}$ under salinity: 20; irradiance: $84 \mu \mathrm{mol}$ photons $\cdot \mathrm{m}^{-2} \cdot \mathrm{s}^{-1}$ and $\mathrm{pH}$ 6.5. The carotenoid content was 0.042 $\mathrm{mg} \cdot \mathrm{g}^{-1} \mathrm{DW}$ under high salinity and irradiance and neutral $\mathrm{pH}$. Therefore, the green microalga Tetraselmis sp. represents an attractive feedstock for human nutrition, aquaculture or bioethanol production.

\section{Acknowledgements}

Authors of this work thank the Tunisian Ministry of higher education and scientific research for providing the funding for this research. This work was supported by the "Agence Universitaire de la Francophonie" (AUF). The authors would like to express their gratitude to Mr Chokri Ghzaiel (ENIS, Sfax) for his help with the English language of the manuscript. 


\section{References}

1. Arbib, Z., Ruiz, J., Alvarez-Diaz, P., Garrido-Perez, C., Perales, J.A., 2014. Capability of different microalgae species for phytoremediation processes: wastewater tertiary treatment, $\mathrm{CO} 2$ bio-fixation and low cost biofuels production. Water Res. 49, 465-474.

2. Baranyi, J., Roberts, T.A., 1994. A dynamic approach to predicting bacterial growth in food. Int. J. Food Microbiol. 23: 277-294.

3. Ben Moussa-Dahmen, I., Chtourou, H., Rezgui, F., Sayadi, S., Dhouib, A. 2016. Salinity stress increases lipid, secondary metabolites and enzyme activity in Amphora subtropicaand Dunaliella sp. for biodiesel production. Bioresour. Technol. 218, 816-825.

4. Box, G.E.P., Behnken, E.W., 1960. Some new three level designs for the study of quantitative variables. Technometrics 2, 455-75.

5. Brányiková, I., Maršálková, B., Doucha, J., Brányik, T., Bišová, K., Zachleder, V., Vítová, M., 2011. Microalgae novel highly efficient starch producers. Biotechnol Bioeng. 108, 766-776.

6. Chang, H.X., Huang, Y. Fu, Q., Liao, Q., Zhu, X., 2016. Kinetic characteristics and modeling of microalgae Chlorella vulgaris growth and $\mathrm{CO}_{2}$ biofixation considering the coupled effects of light intensity and dissolved inorganic carbon. Bioresour Technol. 206, 231-238.

7. Chen, H., Jiang, J.G., 2009. Osmotic responses of Dunaliella to the changes of salinity. J. Cell. Physiol. 219, 251-258.

8. Dahmen, I., Chtourou, H., Jebali, A., Daassi, D., Karray, F., Hassairi, I., Sayadi, S., Abdelkafi, S., Dhouib, A., 2014. Optimisation of the critical medium components for better growth of Picochlorum sp. and the role of stressful environments for higher lipid production. J. Sci. Food Agric. 94, 1628-38.

9. Dammak M., Haase S. M., Miladi R., Ben Amor F., Barkallah M., Gosset D., Pichon C., Huchzermeyer B., Fendri I., Denis M., Abdelkafi S., 2016. Enhanced lipid and biomass production by a newly isolated and identified marine microalga. Lipids Health Dis. 15, 209 


\section{ACCEPTED MANUSCRIPT}

10. Dammak, M., Hadrich, B., Miladi R., Barkallah M., Hentati F., Hachicha R., Laroche C., Michaud P., Fendri I. and Abdelkafi S., 2017. Effects of nutritional conditions on growth and biochemical composition of Tetraselmis sp. Lipids Health Dis. 16, 41.

11. Davey, H.M., Kell, D.B., 1996. Flow cytometry and cell sorting of heterogeneous microbial populations-the importance of single-cell analyses. Microbiol. Rev. 60:641-696.

12. Delattre C., Pierre G., Laroche C., Michaud P. (2016). Production, extraction and characterization of microalgal and cyanobacterial exopolysaccharides. Biotechnol. Adv. 34: $1159-1179$

13. Dragone, G., Fernandes, B.D., Abreu, A.P., Vicente, A.A., Teixeira, J.A., 2011. Nutrient limitation as a strategy for increasing starch accumulation in microalgae. Appl. Energy 88, $3331-3335$

14. El-Kassas, H.Y., El-Sheekh, M.M., 2016. Induction of the synthesis of bioactive compounds of the marine alga Tetraselmis tetrathele (West) Butcher grown under salinity stress. Egyptian Journal of Aquatic Research 42, 385-391.

15. García, N., López-Elías, J.A., Miranda, A., Martínez-Porchas, M., Huerta, N., García, A., 2012. Effect of salinity on growth and chemical composition of the diatom Thalassiosira weissflogii at three culture phases. Latin Am. J. Aquatic Res. 40(2): 435-440.

16. Guillard, R.R.L., 1975. Culture of phytoplankton for feeding marine invertebrates. In Smith, W. L. and Chanley, M. H. (eds), Cultures of Marine Invertebrate Animals. Plenum Press. 29-60.

17. Han, D., Wang, J., Sommerfeld, M., Hu, Q., 2012. Susceptibility and potective mechanisms of motile and non motile cells of Haematococcus pluvialis (Chlorophyceae) to photo-oxidative stress. J. Phycol. 48, 693-705.

18. Hemaiswarya, S., Raja, R., Kumar, R.R., Ganesan, V., Anbazhagan, C., 2011. Microalgae:a sustainable feed source for aquaculture. World J. Microbiol. Biotechnol. 27, 1737-746. 


\section{ACCEPTED MANUSCRIPT}

19. Hirst, S.E., Manners, D.J., Pennies, I.R., 1972. The molecular structure of starch-Type polysaccharides from Haematococcus pluvialis and Tetraselmis carteriiformis. Carbohydr. Res. 22: 5-11.

20. Ho, S., Chen, C., Chang, J., 2012. Effect of light intensity and nitrogen starvation on $\mathrm{CO}_{2}$ fixation and lipid/carbohydrate production of an indigenous microalga Scenedesmus obliquus. Bioresour. Technol. 113, 244-252.

21. Ike, A., Toda, N., Tsuji, N., Hirata, K., Miyamoto, K., 1997. Hygrogen photoproduction from CO2-fixing microalgal biomass: application of halotolerant photosynthetic bacteria. J. Ferment. Bioeng. 84, 606-609.

22. Juneja, A., Ceballos, R.M., Murthy, G.S., 2013. Effects of Environmental Factors and Nutrient Availability on the Biochemical Composition of Algae for Biofuels Production: A Review. Energies, 6, 4607-4638.

23. Khalil, Z., Asker, M.S., El-Sayed, S., Kobbia, I., 2010. Effect of pH on growth and biochemical responses of Dunaliella bardawil and Chlorella ellipsoidea. World J. Microbiol. Biotechnol. 26, 1225-1231.

24. Khatoon, H., Abdu Rahman, N., Banerjee, S., Harun, N., Suleiman, S.S., Zakaria, N.H., Lananan, F., Abdul Hamid, S.H., Endut, A., 2014. Effects of different salinities and pH on the growth and proximate composition of Nannochloropsis sp. and Tetraselmis sp. isolated from South China Sea cultured under control and natural condition. Int. Biodeter. Biodeg. ,95, 11-18.

25. Kirrolia, A., Bishnoi, N.R., Singh, N. 2011. Salinity as a factor affecting the physiological and biochemical traits of Scenedesmus quadricauda. J. Algal Biomass Utilization 2, 28-34.

26. Kirst, G., 1990. Salinity tolerance of eukaryotic marine algae. Ann. Rev. Plant Biol. 41, 21-53.

27. Koca, N., Burdurlu, H.S., Karadeniz, F., 2007. Kinetics of colour changes in dehydrated carrots. J. Food Eng. 78, 449-455. 


\section{ACCEPTED MANUSCRIPT}

28. Kumar, P., Ramakritinan, C.M. Kumaraguru, A.K., 2010. Solvent extraction and spectrophotometric determination of pigments of some algal species from the shore of puthumadam, southeast coast of India. Int. J. Oceans Oceanography 4: 29-34.

29. Li, T., Gargouri, M., Feng, J., Park, J.J., Gao, D., Miao, C., Dong, T., Gang, D.R., Chen S., 2015. Regulation of starch and lipid accumulation in a microalga Chlorella sorokiniana. Bioresour. Technol.180, 250-257.

30. Li, Y., Sommerfeld, M., Chen, F., Hu, Q., 2010. Effect of photon flux densities on regulation of carotenogenesis and cell viability of Haematococcus pluvialis (Chlorophyceae). J. Appl. Phycol. 22, 253-263.

31. Lichtenthaler, H.K., Wellburn, A.R., 1985. Determination of total carotenoids and chlorophylls A and B or leaf in dissolved solvents. Biochem. Soc. Trans. 11: 591-592.

32. Markou, G., Angelidaki, I., Georgakakis, D., 2012. Microalgal carbohydrates: an overview of the factors influencing carbohydrates production, and of main bioconversion technologies for production of biofuels. Appl. Microbiol. Biotechnol. 96, 631-645.

33. Mohamed, M.S., Tan, J.S., Kadkhodaei, S., Mohamad, R., Mokhtar, M.N., Ariff, A.B., 2014. Kinetics and modeling of microalga Tetraselmis sp. FTC 209 growth with respect to its adaptation toward different trophic conditions. Biochem. Eng. J. 88, 30-41.

34. Murata, N., Takahashi, S., Nishiyama, Y., Allakhverdiev, S.I., 2007. Photoinhibition of photosystem II under environmental stress. Biochim Biophys. Acta 1767, 414- 421.

35. Nguyen, B.T., Rittmann, B.E., 2016. Effects of inorganic carbon and pH on growth kinetics of Synechocystis sp.PCC 6803. Algal Res. 19, 363-369.

36. Pancha, I., Chokshi, K., Mishra, S., 2015. Enhanced biofuel production potential with nutritional stress amelioration through optimization of carbon source and light intensity in Scenedesmus sp. CCNM 1077. Bioresour. Technol. 179, 565-572. 


\section{ACCEPTED MANUSCRIPT}

37. Richter, D., Kirst, G., 1987. D-Mannitol dehydrogenase and D-mannitol-1-phosphate dehydrogenase in Platymonas subcordiformis: some characteristics and their role in osmotic adaptation. Planta 170, 528-534.

38. Saddoud, A., Abdelkafi, S., Sayadi, S., 2009. Effects of domestic wastewater toxicity on anaerobic membrane bioreactor (MBR) performances. Environ. Technol. 30, 1361-1369.

39. Schmidt, J.J., Gagnon, G.A., Jamieson, R.C., 2016. Microalgae growth and phosphorus uptake in wastewater under simulated cold region conditions. Ecol. Eng. 95, 588-593.

40. Siaut, M., Cuine, S., Cagnon, C., Fessler, B., Nguyen, M., Carrier, P., Beyly, A., Beisson, F., Triantaphylides, C., Li-Beisson, Y., Peltier, G., 2011. Oil accumulation in the model green alga Chlamydomonas reinhardtii: characterization, variability between common laboratory strains and relationship with starch reserves. BMC Biotechnol. 11, 7.

41. Sudhir, P., Murthy, S., 2004. Effects of salt stress on basic processes of photosynthesis. Photosynthetica 42, 481-486.

42. Sun, X., Cao, Y., Xu, H., Liu, Y., Sun, J., Qiao, D., Cao, Y., 2014. Effect of nitrogen starvation, light intensity and iron on triacylglyceride/carbohydrate production and fatty acid profile of Neochloris oleobundans HK-129 by a two stage process. Bioresour. Technol. $155,204-212$.

43. Strizh, I.G., Popova, L.G., Balnokin, Y.V., 2004. Physiological aspects of adaptation of the marinemicroalga Tetraselmis (Platymonas) viridis to various medium salinity. Rus. J. Plant Physiol. 51, 197-204.

44. Takeshita, T., Ota, S., Yamazaki, T., Hirata, A., Zachleder, V., Kawano, S., 2014. Starch and lipid accumulation in eight strains of six Chlorella species under comparatively high light intensity and aeration culture conditions. Bioresour. Technol. 158, 127-134.

45. Tanaka, A., Tanaka, R., 2006. Chlorophyll metabolism. Curr. Opin. Plant. Biol. 9 (3), 248255. 


\section{ACCEPTED MANUSCRIPU}

46. Vogels, M., Zoeckler, R., Stasiw, D., Cerny, L., 1975. P. F. Verhulst's, “'notice sur la loi que la populations suit dans son accroissement" from correspondence mathematique et physique. Ghent, vol. X, 1838. J. Biol. Physics 3, 183-192.

47. Xiao, Z., Storms, R., Tsang, A., 2006. A quantitative starch-iodine method for measuring alpha-amylase and glucoamylase activities. Anal. Biochem. 351(1), 146-8.

48. Yao, Ch., Ai, J., Cao, X., Xue, S., Zhang, W., 2012. Enhancing starch production of a marine green microalga Tetraselmis subcordiformis through nutrient limitation. Bioresour. Technol. $118,438-444$.

49. Yao, Ch.H., Ai, J.N., Cao, X.P., Xue, S., 2013. Salinity manipulation as an effective method for enhanced starch production in the marine microalga Tetraselmis subcordiformis. Bioresour. Technol. 146, 663-671.

50. Zwietering, M.H., Jongenburger, I., Rombouts, F.M., Van't Riet, K., 1990. Modeling of the bacterial growth curve. Appl. Environ. Microbiol. 56 (6) 1875-1881. 


\section{Figure captions}

Fig. 1. Cells absorbance measurements and the four models (logistic, logistic with lag, modified Gompertz and Baranyi-Roberts, respectively) predicted values for Tetraselmis sp. growth cultured under basic environmental conditions (salinity: 40; irradiance: $84 \mu \mathrm{mol}$ photons $\cdot \mathrm{m}^{-2} \cdot \mathrm{s}^{-1} ; \mathrm{pH} 7$; temperature: $25^{\circ} \mathrm{C}$ ). Bars are means of duplications $\pm \mathrm{SD}$

Fig. 2. Comparison between experimental and predicted data. Total chlorophyll (A), Carotenoid (B) and Starch (C) contents.

Fig. 3. Contour plots and the corresponding response surface plot showing the effect of environmental culture conditions on total chlorophyll content $\left(\mathrm{mg} \cdot \mathrm{g}^{-1} \mathrm{DW}\right)$ at $\mathrm{pH} 6.5$ (A), carotenoids content $\left(\mathrm{mg} \cdot \mathrm{g}^{-1} \mathrm{DW}\right)$ at $\mathrm{pH}: 7$ (B) and starch content $\left(\mathrm{g} \cdot \mathrm{g}^{-1} \mathrm{DW}\right)$ at $\mathrm{pH} 7$ (C).

Fig. 4. The ratio of chlorophyll content / optimal value results (A) and the ratio of chlorophyll autofluorescence / optimal value results (B) related to the RSM runs.

Fig. 5. Correlation between cellular contents of total chlorophylls estimated by gravimetric analysis and by flow cytometry 'FL3 channel' (excitation, 488; emission wavelengths, 613/682 $\mathrm{nm})$. 


\section{Highlights}

- Four non-linear models were evaluated for predicting cell-growth kinetic.

- Baranyi-Roberts model was selected to assess the microalga growth-kinetic values

- The greatest content-values achieved for chlorophyll and carotenoid compounds

- Combination of decreased salinity and light stress contributed to starch accumulation 

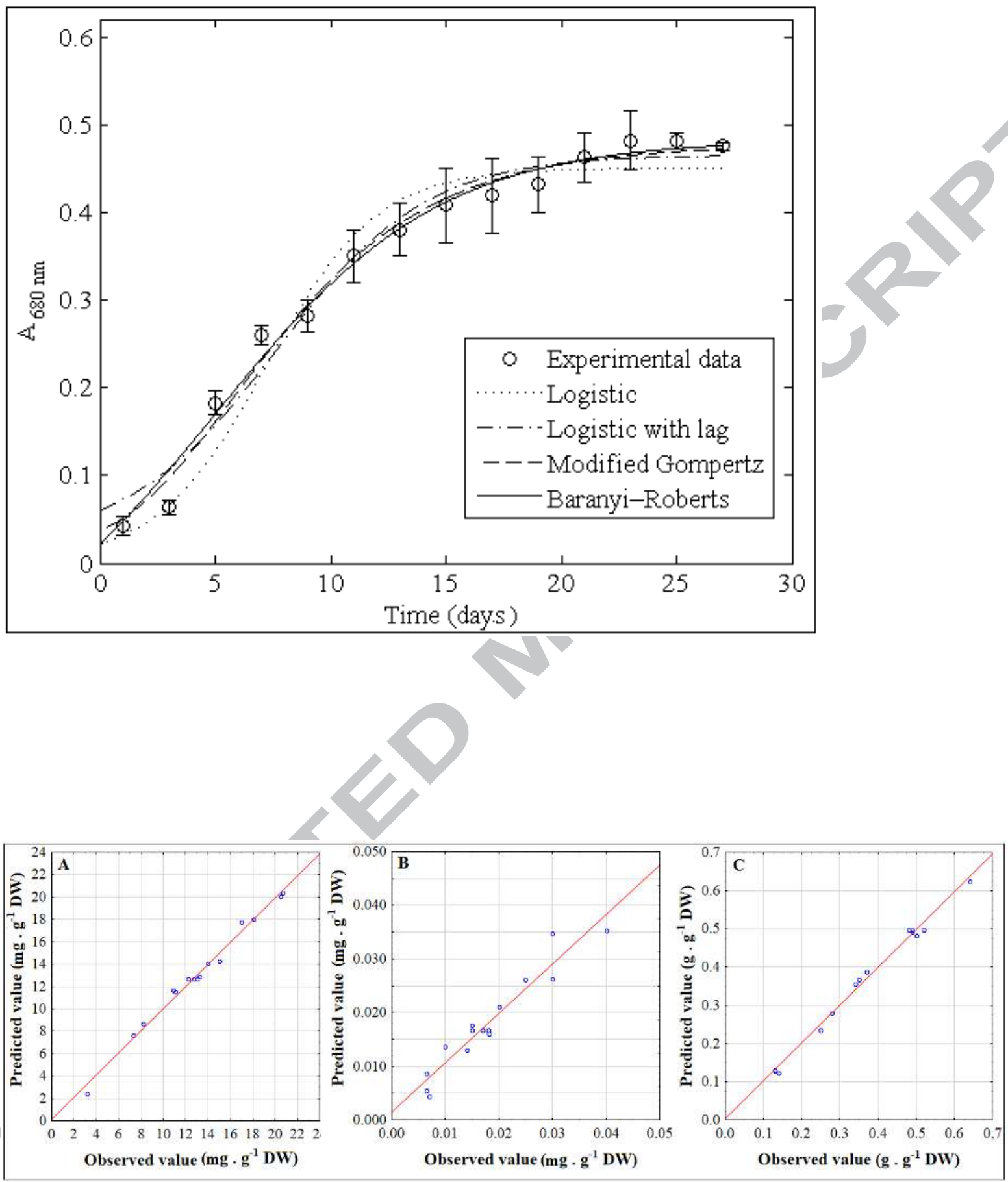


\section{ACCEPTED MANUSCRIPT}
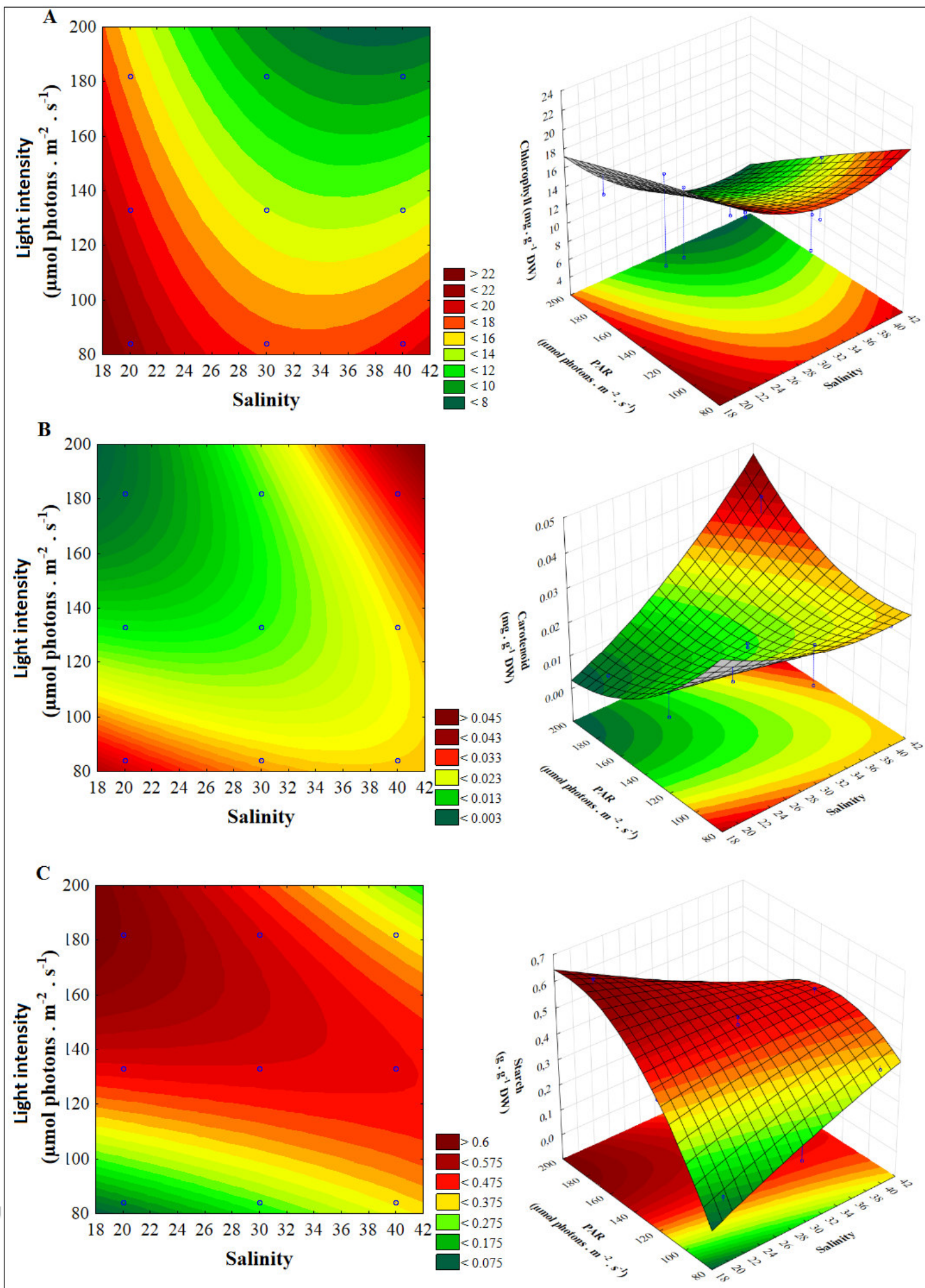


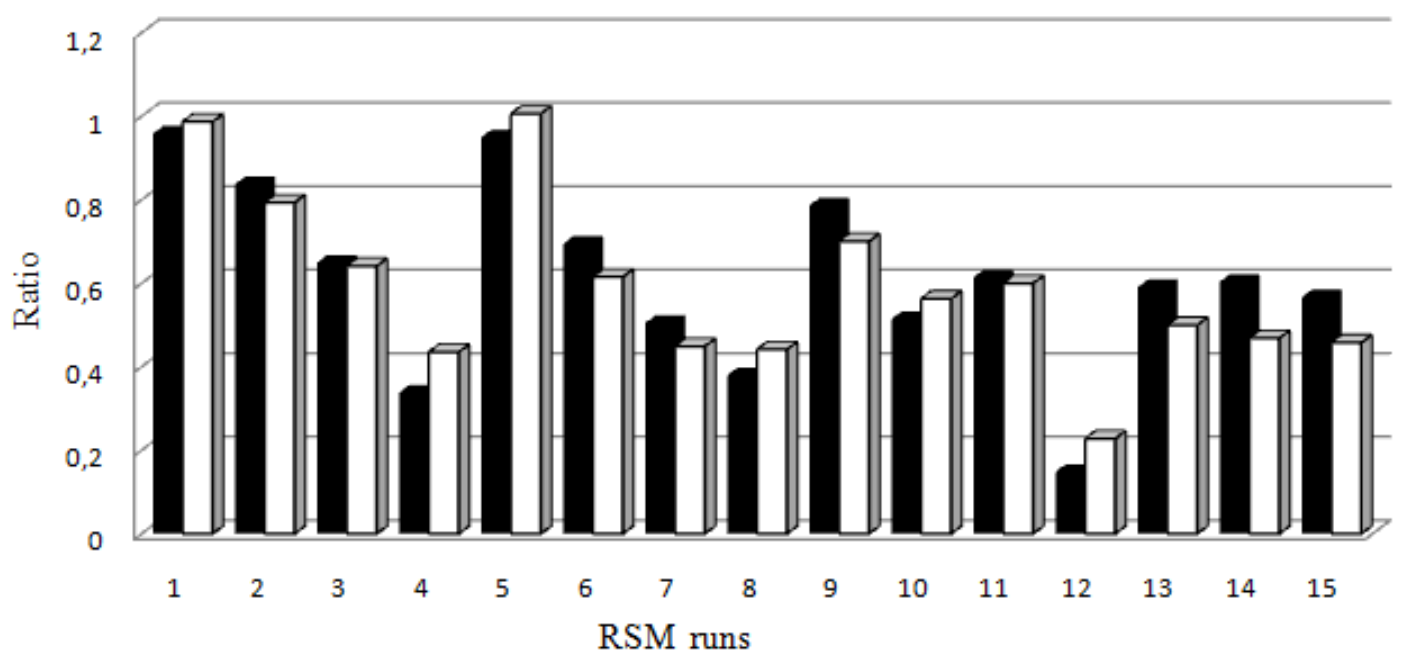

- Ratio A ( chlorophyll content (mg - g-1 DW)/optimal value)

$\square$ Ratio B ( chlorophyll autofluorescence (a.u.) / optimal value)

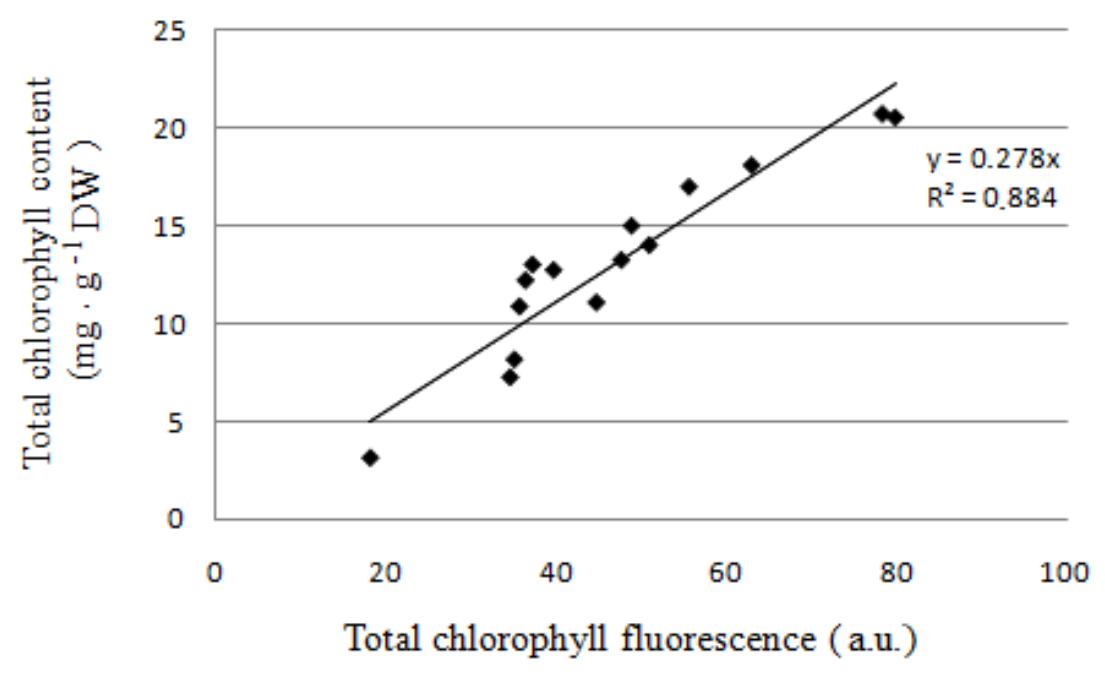


Table 1

Selected variable values and experimental levels for optimizing environmental conditions.

\begin{tabular}{|l|l|l|l|l|}
\hline \multicolumn{1}{|c|}{ Factors } & \multicolumn{1}{c|}{ Symbol } & \multicolumn{3}{c|}{ Coded levels } \\
\hline & \multicolumn{1}{|c|}{1} & 0 & +1 \\
\hline Salinity & $x_{1}$ & 20 & 30 & 40 \\
\hline $\begin{array}{l}\text { Irradiance }(\mu \mathrm{mol} \\
\left.\text { photons } \cdot \mathrm{m}^{-2} \cdot \mathrm{s}^{-1}\right)\end{array}$ & $x_{2}$ & 84 & 133 & 182 \\
\hline $\mathrm{pH}$ & $x_{3}$ & 6 & 7 & 8 \\
\hline
\end{tabular}

Table 2 Experimental results of Box-Behnken Design.

\begin{tabular}{|c|c|c|c|c|c|c|}
\hline \multirow{2}{*}{ Run } & \multicolumn{3}{|c|}{ Factors } & \multicolumn{3}{|c|}{ Responses } \\
\hline & $x_{1}$ & $x_{2}$ & $x_{3}$ & $Y_{1}$ & $Y_{2}$ & $Y_{3}$ \\
\hline 1 & $20(-1)$ & $84(-1)$ & $7(0)$ & 20.69 & 0.030 & 0.14 \\
\hline 2 & $40(+1)$ & $84(-1)$ & $7(0)$ & 18.08 & 0.025 & 0.34 \\
\hline 3 & $20(-1)$ & $182(+1)$ & $7(0)$ & 14.02 & 0.006 & 0.64 \\
\hline 4 & $40(+1)$ & $182(+1)$ & $7(0)$ & 7.30 & 0.040 & 0.35 \\
\hline 5 & $20(-1)$ & $133(0)$ & $6(-1)$ & 20.51 & 0.007 & 0.34 \\
\hline 6 & $40(+1)$ & $133(0)$ & $6(-1)$ & 15.00 & 0.020 & 0.50 \\
\hline 7 & $20(-1)$ & $133(0)$ & $8(+1)$ & 10.90 & 0.014 & 0.37 \\
\hline 8 & $40(+1)$ & $133(0)$ & $8(+1)$ & 8.20 & 0.015 & 0.25 \\
\hline 9 & $30(0)$ & $84(-1)$ & $6(-1)$ & 16.98 & 0.018 & 0.13 \\
\hline 10 & $30(0)$ & $182(+1)$ & $6(-1)$ & 11.10 & 0.010 & 0.49 \\
\hline 11 & $30(0)$ & $84(-1)$ & $8(+1)$ & 13.26 & 0.030 & 0.13 \\
\hline 12 & $30(0)$ & $182(+1)$ & $8(+1)$ & 3.20 & 0.006 & 0.28 \\
\hline 13 & $30(0)$ & $133(0)$ & $7(0)$ & 12.75 & 0.018 & 0.49 \\
\hline 14 & $30(0)$ & $133(0)$ & $7(0)$ & 13.03 & 0.015 & 0.52 \\
\hline 15 & $30(0)$ & $133(0)$ & $7(0)$ & 12.23 & 0.017 & 0.48 \\
\hline
\end{tabular}

$Y_{l}$ : Total chlorophyll content $\left(\mathrm{mg} \cdot \mathrm{g}^{-1} \mathrm{DW}\right) ; Y_{2}$ : carotenoid content $\left(\mathrm{mg} \cdot \mathrm{g}^{-1} \mathrm{DW}\right) ; Y_{3}$ : starch content $\left(\mathrm{g} \cdot \mathrm{g}^{-1} \mathrm{DW}\right)$. 
Table 3

Performance parameters and kinetic data of the four Tetraselmis sp. growth models.

\begin{tabular}{lcccc}
\hline \multicolumn{1}{c}{ Models } & Logistic & $\begin{array}{c}\text { Logistic with } \\
\text { lag }\end{array}$ & $\begin{array}{c}\text { Modified } \\
\text { Gompertz }\end{array}$ & $\begin{array}{c}\text { Baranyi- } \\
\text { Roberts }\end{array}$ \\
\hline Kinetic parameters & & & & \\
\hline$X_{\max }\left(\mathrm{A}_{680 \mathrm{~nm}}\right)$ & 0.451 & 0.466 & 0.477 & 0.483 \\
$\mu_{\max }\left(\right.$ day $\left.^{-1}\right)$ & 0.416 & 0.034 & 0.035 & 0.206 \\
$\lambda($ day) & - & 1.145 & 1.028 & 5.367 \\
\hline Statistical parameters & & & & \\
\hline $\mathrm{R}^{2}$ & 0.961 & 0.976 & 0.987 & 0.987 \\
Adj R $^{2}$ & 0.957 & 0.971 & 0.985 & 0.985 \\
SSE & 0.012 & 0.007 & 0.004 & 0.004 \\
RMSE & 0.031 & 0.026 & 0.019 & 0.018 \\
\hline
\end{tabular}

Table 4 Variance analysis of total chlorophyll production model.

\begin{tabular}{llllll}
\hline Source & SS & Df & MS & $F$ value & $P$ value* \\
\hline & & & & & \\
$x_{1}$ & 38.45 & 1 & 38.45 & 233.35 & $0.004^{*}$ \\
$x_{2}$ & 139.36 & 1 & 139.36 & 845.64 & $0.001^{*}$ \\
$x_{3}$ & 98.21 & 1 & 98.21 & 595.935 & $0.002^{*}$ \\
$x_{1} x_{2}$ & 4.223 & 1 & 4.223 & 25.625 & $0.036^{*}$ \\
$x_{1} x_{3}$ & 1.974 & 1 & 1.974 & 11.978 & 0.074 \\
$x_{2} x_{3}$ & 4.368 & 1 & 4.368 & 26.505 & $0.035^{*}$ \\
$x_{1}{ }^{2}$ & 21.89 & 1 & 21.89 & 132.84 & $0.007^{*}$ \\
$x_{2}{ }^{2}$ & 0.025 & 1 & 0.025 & 0.152 & 0.733 \\
$x_{3}$ & 7.789 & 1 & 7.789 & 47.268 & $0.020^{*}$ \\
Lack of fit & 3.309 & 3 & 1.103 & 6.694 & 0.132 \\
Pure error & 0.329 & 2 & 0.164 & & \\
Total & 322.199 & 14 & & & \\
\hline
\end{tabular}

$\mathrm{R}^{2}=98.87 \% ; \operatorname{AdjR}^{2}=96.84 \% ; *$ Significant at $P$-value $<0.05$ 


\section{ACCEPTED MANUSCRIPT}

Table 5 Variance analysis of carotenoid production model.

\begin{tabular}{llllll}
\hline Source & SS & Df & MS & $F$ value & $P$ value \\
\hline$x_{1}$ & 0.0002 & 1 & 0.0002 & 96.30 & $0.01^{*}$ \\
$x_{2}$ & 0.0002 & 1 & 0.0002 & 86.57 & $0.01^{*}$ \\
$x_{3}$ & 0.00001 & 1 & 0.00001 & 5.79 & 0.13 \\
$x_{1} x_{2}$ & 0.0004 & 1 & 0.0004 & 158.81 & $0.006^{*}$ \\
$x_{1} x_{3}$ & 0.00004 & 1 & 0.00004 & 15.68 & 0.058 \\
$x_{2} x_{3}$ & 0.00006 & 1 & 0.00006 & 25.08 & $0.037^{*}$ \\
$x_{1}^{2}$ & 0.00004 & 1 & 0.00004 & 17.01 & 0.05 \\
$x_{2}{ }^{2}$ & 0.0001 & 1 & 0.0001 & 46.64 & $0.02^{*}$ \\
$x_{3}$ & 0.0001 & 1 & 0.0001 & 55.47 & $0.017^{*}$ \\
Lack of Fit & 0.000099 & 3 & 0.000033 & 14.10 & 0.06 \\
Pure error & 0.000005 & 2 & 0.000002 & & \\
Total & 0.0013 & 14 & & & \\
\hline
\end{tabular}

$\mathrm{R}^{2}=92.10 \% ; \operatorname{AdjR}^{2}=77.87 \%$; * Significant at $P$-value $<0.05$.

Table 6 Variance analysis of starch production model.

\begin{tabular}{llllll}
\hline Source & SS & Df & MS & $F$ value & $P$ value* \\
\hline & & & & & \\
$x_{1}$ & 0.0003 & 1 & 0.0003 & 0.721 & 0.485 \\
$x_{2}$ & 0.130 & 1 & 0.130 & 300.115 & $0.003^{*}$ \\
$x_{3}$ & 0.023 & 1 & 0.023 & 53.336 & $0.018^{*}$ \\
$x_{1} x_{2}$ & 0.060 & 1 & 0.060 & 138.519 & $0.007^{*}$ \\
$x_{1} x_{3}$ & 0.020 & 1 & 0.020 & 45.230 & $0.021^{*}$ \\
$x_{2} x_{3}$ & 0.011 & 1 & 0.011 & 25.442 & $0.037^{*}$ \\
$x_{1}{ }^{2}$ & 0.0004 & 1 & 0.0004 & 1.0000 & $0.422^{*}$ \\
$x_{2}{ }^{2}$ & 0.052 & 1 & 0.052 & 119.313 & $0.008^{*}$ \\
$x_{3}$ & 0.054 & 1 & 0.054 & 124.408 & $0.008^{*}$ \\
Lack of fit & 0.002 & 3 & 0.0007 & 1.634 & 0.401 \\
Pure error & 0.0008 & 2 & 0.0004 & & \\
Total & 0.345 & 14 & & & \\
\hline
\end{tabular}

$\mathrm{R}^{2}=99.13 \% ; \mathrm{AdjR}^{2}=97.57 \%$; * Significant at $P$-value $<0.05$. 